\title{
Black people and psychiatry in the UK
}

\author{
An alternative to institutional care ${ }^{\star}$
}
Errol Francis, Afro-Caribbean Mental Health Association, London; JACK David and Nancy Johnson, Core \& Cluster Project, Harambee, Birmingham; and S. P. SaSHIDHARAN, Department of Psychiatry, University of Birmingham, All Saints Hospital, Birmingham B18 5SD

Our aim in this paper is to examine the current practice of psychiatry in relation to race or ethnicity in England. The problems that European psychiatry has in relation to black people in a white and predominantly racist society and the responses to these from within the professional sphere are only one aspect of our current topic. We merely mention these to contextualise the problems black people experience as a result of institutional psychiatry. Our main aim in this paper is to articulate the oppression black people experience in relation to conventional psychiatry and to seek ways of confronting and changing this, very much as part of the larger, black struggle in the UK. We believe that the alternative that we propose, based on black experience of psychiatry, is equally valid in other contexts where questions of disadvantage and discrimination are the overriding themes. Although the theoretical basis of our work is grounded on issues such as inequality and structural oppression and the need to confront and change them, a detailed analysis of these topics is beyond the scope of this paper. Instead, we examine the practice of professional psychiatry in relation to black people in the UK and argue that the model that is imposed on us is antithetical to the interests of black minority groups. We also look at practical ways in which our community is beginning to organise in challenging such professional orthodoxy.

\section{Race and psychiatry in Britain - the crisis in mental health}

At present, there is a crisis in British psychiatry around the issue of race. Over the last 20 to 30 years, British psychiatry has had to face up to the fact that black immigrants and their descendents are making demands on the profession, and this demand is expected to increase with time as the minority population becomes more numerous and visible. Initially,

*An earlier version of this paper was presented at the European Symposium on Psychiatry Without Asylums, Bologna, Italy, 20-22 October 1988. the historical remnants of colonial psychiatry that had survived in the form of 'cultural psychiatry' within the European tradition were called upon to elucidate the problems inherent in the clinical encounter between white (mostly) psychiatrists and black patients. However, the demand that black patients were making was not entirely understandable in terms of exotic variations in symptoms, meanings or practice. It appeared to go beyond the predetermined and professionally limited concerns of the practice of psychiatry. Also, the question of race was not simply another discrete demographic factor that could be understood within a medical theory of cause and effect but one that touched on and reawakened doubts about psychiatry's function and role within our society.

The disproportionate numbers of black, mainly Afro-Caribbean, people in English psychiatric hospitals is the central issue around which much of this debate about race and psychiatry has developed in the last decade. Conventional psychiatric thinking in this area suggests that such over-representation of black people in psychiatric facilities, particularly for the diagnosis schizophrenia, is indicative of a racial or ethnic vulnerability to a major mental illness.

Such an interpretation, however, is fraught with major problems. For example, evidence from many studies would appear to suggest that the diagnosis of schizophrenia is likely to be more unreliable, less specific, lacking stability over time and more readily and uncritically used in black patients than among white patients. There is strong support for the argument that 'misdiagnosis' of schizophrenia accounts for some of the excess of Afro-Caribbean admissions to psychiatric hospitals. Interestingly, what such evidence points to is the fact that nosological categories in psychiatry, derived from within a Eurocentric theory and largely based on observations in European settings, are deficient and misleading in categorising and describing the experience of non-European people. Secondly, the diagnostic process - the initial clinical encounter between a European psychiatrist and a black person in a European setting - is fraught 
with difficulties that could seriously distort clinical assessment.

The dissatisfaction that many black clients experience is not exclusively concerned with the question of diagnosis or misdiagnosis. The major failure of psychiatry in relation to ethnic minorities in England is to do with the day-to-day experience of black clients in our mental institutions. They are more likely than their white counterparts to have been brought into hospitals against their wishes (i.e. compulsorily admitted, usually through the police under sections of the mental health legislation) and, in most instances, seen as requiring coercion and seclusion within hospitals. Black patients are also more likely than white patients to be forcibly treated, detained in secure facilities such as locked wards, regional secure units and special hospitals. On average, their treatment is more heavily reliant on medication or other physical methods, usually to the exclusion of psychotherapy or any meaningful social interventions. In many ways, this kind of psychiatric experience is not totally divorced from the overall experience of black people in England where their status is one of marginality, and their experience is largely one of deprivation, disadvantage and discrimination. The marginal status that the blacks occupy is conventionally, and we believe wrongly, attibuted to a social pathology of culture. Since such pathology is often located at the individual level, and since it is essentially seen as disruptive, the visible oppression of black people is founded on themes of law and order, one of control and coercion. It comes as no surprise therefore that black people are over-represented in all kinds of correctional and coercive institutions such as prisons and psychiatric hospitals in the UK.

Black people in turn have a predominantly negative view about psychiatry and related institutions. There can be no question that the mistrust and suspicion thus created compound some of the problems within hospitals and various clinical situations.

At the same time there is a crisis in the black community too, which feels that the available resources in the mental health field are inappropriate to their needs but that no alternatives exist for those in need. Again, this lack of choice and the sense of powerlessness that black people experience in relation to psychiatry are just another aspect of black oppression.

\section{Black community's response}

We will describe two initiatives which are responses to the mental health need within the black community and the crisis in institutional psychiatry. Both arose out of a sense of despair experienced by local black communities at the total failure of mental health services. Their main aims were to provide appropriate forms of care and support while seeking to challenge the racial inequalities in the health and social welfare fields.

There are two issues in relation to service delivery which these alternative to conventional psychiatry recognise as crucial in strategic terms. One is concerned with resources, buildings and other provisions, finance and skills necessary in the attempt to provide care. The second issue is that of practice or what needs to be done when trying to help those who are recognised as needing help. In other words, a coherent theory that informs particular forms of practice has to be evolved at the same time as the community reclaiming the resources and the necessary structures set up in the name of black people. We are convinced that success in this area provides an opportunity to create the conditions necessary for the emergence of a kind of psychiatry that is liberated from its institutional base and current structural affiliations.

\section{Harambee Core and Cluster Project}

This is a black mental health project set up in Birmingham. The city of Birmingham has one of the highest concentrations of black population outside London and there is a long history of black settlement in and around the city. The ecological distribution of black people in Birmingham follows the conventional pattern in Western Europe-poor, economically and socially disadvantaged groups living in decaying, overcrowded inner city areas.

In Handsworth and the surrounding areas of Birmingham, the black population has experienced continuing problems with the local psychiatric institutions for a number of years. Much of this disaffection stems from the perception of psychiatry as either unnecessarily coercive or therapeutically ineffective and negligent of the social and material needs that underlie the mental health problems of black people locally.

Since homelessness was also a major problem among the black community in Handsworth, attempts were being made by local black people to set up hostels for single homeless and it soon became clear that many of the residents showed signs of considerable mental distress. A large proportion of these young clients had been in psychiatric hospitals in the past and many of them carried the stigma of a serious psychiatric diagnosis and secondary problems consequent upon inception into psychiatric care. At the same time, evidence from the local psychiatric hospital suggested that their discharged, mostly black patients tended to gravitate to Handsworth and surrounding areas, partly because of the proliferation of cheap lodging houses there. Such social drift was encouraged by failure of statutory and voluntary services to provide credible aftercare facilities to this client group. 
The Harambee Housing Association and the Core and Cluster Mental Health Project are specifically set up to provide some help for this neglected client group. The project is aimed at dealing with issues such as loss of self-esteem, loss of communication skills, rejection by family and peer group, inability to seek help or support and lack of appropriate and stable accommodation - all important in problems identified in the client group. Although many of these problems were shared by the majority of psychiatric patients irrespective of ethnicity, especially those in long-term institutional care, being black as well as being labelled as mental patients increased their sense of marginalisation and seriously undermined their ability to deal with multiple disadvantages which follow from being doubly 'deviant'. Much of the initial work undertaken by the project is therefore directed at achieving a sense of independence and mastery in the clients, through a shared, problem-orientated approach which emphasises the social support and material help available through the local black community.

Phased accommodation based on continuous assessment, provided by black workers drawn from a variety of backgrounds, has played a crucial part in getting the project established. In 1985, when the first phase of the accommodation was open, it provided seven places. Since that time, the total places available has increased to 21 , with a core hostel catering for new referrals, providing assessment and support for those requiring maximum help. Many of them from the core hostel subsequently move on to the cluster hostels. Eventually people progress to independent or shared houses/flats.

Although residential accommodation is a central issue around which much of the project has been built up, Harambee has been actively involved in developing models of care and support for individuals with often intractable psychological and material problems. With the cooperation of other locally based black groups, clients are involved in a variety of activities aimed at achieving functional independence. Similarly, through programmes of client advocacy, local hospital resources and social services have been attracted towards supporting the project. The key here is one of making use of the skills and experience of other professionals in the support/ counselling programmes and other 'treatments' with the direction of such interventions being determined by the members of the project. In this context, attempts are made to utilise the existing services in ways that do not threaten the autonomy and independence of the project. The lesson that has been learnt is that technical and material help available from psychiatrists and other designated mental health workers is useful to the project's work but is not a prerequisite for effective intervention. The professional hegemony that psychiatry has in the area of mental health is thus constantly being held in check.

The project has encouraged the involvement of the local community in its work. Relatives and friends who were distanced from the clients during their periods in institutional care are slowly brought back into the social network available and often this involves a re-examination of the context within which the initial 'break-down' occurred. Much of the effort is directed towards a greater sense of involvement in repairing and healing the damage and dislocation many of the clients had experienced.

\section{Afro-Caribbean Mental Health Association}

While the Core and Cluster project of Harambee evolved from a concern about the housing needs of single black men and women, the London-based Afro-Caribbean Mental Health Association (ACMHA) grew out of a recognition that black patients in psychiatric hospital were receiving inferior and, mostly, inappropriate care.

ACMHA was formed in 1982 by black people in Brixton as a response to what was seen as inferior and inappropriate treatment received by black patients in the local hospitals. The local experience was also vindicated by observations elsewhere in the country that black patients in psychiatric facilities were victims of professional ignorance and neglect resulting from pervasive but subtle racist stereotyping.

Since professional concern about these apparent and serious problems appeared to be rather muted, the local black community in Brixton, especially relatives and friends of black patients in mental facilities, decided to find out whether something could be done to change the situation and the ACMHA was set up.

Initially, the organisation worked mainly as a pressure group, campaigning both locally and nationally on issues around race and mental health. Individual cases of black clients who had particular problems in dealing with professional psychiatry were supported and much effort went into making local psychiatric services more sensitive to the needs of black clients, and professionals more accessible to a dialogue about clinical practices and the appropriateness of their interventions. It soon became clear that client advocacy work and attempts at influencing practices and policies within the rigid and somewhat uncertain local services were of only limited benefit and the atavistic notions within the professional ranks about black people were a major impediment to procuring adequate and appropriate mental health care for the largely disadvantaged local population. In addition, the nature of psychiatric practice appeared to be dominated by narrow professional/economic considerations and there was 
little real possibility of change. ACMHA soon decided to work towards creating an alternative to institutional psychiatry rather than be exclusively concerned with trying to change the practices and policies within the local hospitals and other statutory agencies. The first step in this direction was setting up a community mental health centre in an attempt to provide an alternative to institution-based care, as well as to raise the standard of care available in South London.

The Association's base is in the heart of the black community in Brixton, and with the resources of a multidisciplinary team comprising social workers, nurses, therapists, counsellors, a legal adviser, a housing officer, a researcher and a volunteer organiser, it is now possible to offer a variety of services.

(a) Clinical advocacy, where clients can be referred by themselves or others if it is felt that the diagnosis or treatment plan made by mainstream psychiatric services does not accord with the client's experience or wishes. By performing an alternative assessment on behalf of the client, ACMHA is able to negotiate with statutory carers for a different approach to be taken.

(b) Alternative treatment is provided in the form of psychotherapy, counselling, groupwork or acupressure and relaxation therapies for those clients who do not benefit from the predominant use of psychotropic medication in mainstream psychiatric treatment.

(c) Joint treatment work is conducted through collaboration with other carers who are not sure of how to work with black patients.

(d) Legal advocacy is provided for those clients wishing to challenge their compulsory detention under the Mental Health Act and for those involved in criminal proceedings where their mental health is at issue.

(e) Informal caring is arranged through the use of volunteers to provide non-professional support for those clients trying to re-establish their lives after being in hospital and for those trying to re-establish links with social networks following hospitalisation.

In addition to the provision of these services, ACMHA is trying to construct an alternative knowledge base about black people and mental health through the development of research projects in key areas of concern. Studies are presently being conducted in the areas of clinical practice, processes which underlie hospital admissions, black people's attitude and satisfaction with psychiatry and the overlap between psychiatry and the criminal justice system as it affects young black people.

On average, 40 clients per month are referred to ACMHA. Half of these referrals are self-referrals and the rest are almost equally split between voluntary and statutory agencies referring clients with whom they are having difficulties. About $80 \%$ of all referrals have a housing component, in that they are seeking special accommodation or they simply wish to move from unsatisfactory housing which may be affecting their mental health. The major part of our caseload, however, is taken up with counselling, long-term therapy and short-term advice and information.

Through these activities, ACMHA is attempting to influence psychiatry at the level of theory and practice. In particular, we believe that not only must psychiatry be purged of its racist legacy (the inherited theories of inferiority and danger) but the institutional structure must also be changed so that the needs of black people can be met.

\section{Conclusion}

We believe that these two organisations, the Harambee Core and Cluster project and the AfroCaribbean Mental Health Association, are not merely responding to deficiencies in existing services but they are proposing credible alternatives to conventional psychiatry. By organising around issues of race and racism and by emphasising the political nature of much of psychiatry, we have been able to initiate our actions from a truly community level. Although the failure of institutional psychiatry in responding to the needs of an oppressed minority provided these projects with their initial momentum, what has emerged subsequently is not a culturally or ethnically sensitive variant of the conventional model, but an alternative based on the perceived needs of the community and driven by an impatience and disquiet felt by many of the victims of institutional psychiatry.

The two projects that we have described have developed their activities around differing needs as felt by the local community. One is a residential facility while the other is more actively engaged in client advocacy. There are also differences in the emphasis given to various aspects of the mental health work, professional involvement and staffing structure, etc. Together, they provide a blueprint on the basis which an exciting alternative to institutional psychiatry is possible. 